\title{
Maximising the usefulness of flood risk assessment for the River Vistula in Warsaw
}

\author{
A. Kiczko' ${ }^{1}$, R. J. Romanowicz ${ }^{2}$, M. Osuch ${ }^{2}$, and E. Karamuz ${ }^{2}$ \\ ${ }^{1}$ Warsaw University of Life Sciences - SGGW, Warsaw, Poland \\ ${ }^{2}$ Institute of Geophysics Polish Academy of Sciences, ul. Ksiecia Janusza 64, 01-452 Warsaw, Poland \\ Correspondence to: R. J. Romanowicz (romanowicz@igf.edu.pl)
}

Received: 14 May 2013 - Published in Nat. Hazards Earth Syst. Sci. Discuss.: 13 June 2013

Revised: 15 November 2013 - Accepted: 18 November 2013 - Published: 23 December 2013

\begin{abstract}
The derivation of the flood risk maps requires an estimation of maximum inundation extent for a flood with a given return period, e.g. 100 or $500 \mathrm{yr}$. The results of numerical simulations of flood wave propagation are used to overcome the lack of relevant observations. In practice, deterministic 1-D models are used for that purpose. The solution of a 1-D model depends on the initial and boundary conditions and estimates of model parameters based on the available noisy observations. Therefore, there is a large uncertainty involved in the derivation of flood risk maps using a single realisation of a flow model. Bayesian conditioning based on multiple model simulations can be used to quantify this uncertainty; however, it is too computer-time demanding to be applied in flood risk assessment in practice, without further flow routing model simplifications. We propose robust and feasible methodology for estimating flood risk. In order to decrease the computation times the assumption of a gradually varied flow and the application of a steady state flow routing model is introduced. The aim of this work is an analysis of the influence of those simplifying assumptions and uncertainty of observations and modelling errors on flood inundation mapping and a quantitative comparison with deterministic flood extent maps. Apart from the uncertainty related to the model structure and its parameters, the uncertainty of the estimated flood wave with a specified probability of return period (so-called 1-in-10 yr, or 1-in-100 yr flood) is also taken into account. In order to derive the uncertainty of inundation extent conditioned on the design flood, the probabilities related to the design wave and flow model uncertainties are integrated. In the present paper that integration is done whilst taking into account the dependence of roughness coefficients on discharge. The roughness is parameterised based
\end{abstract}

on maximum annual discharges. This approach allows for the relationship between flood extent and flow values to be derived, thus giving a cumulative assessment of flood risk. The methods are illustrated using the Warsaw reach of the River Vistula as a case study. The results indicate that deterministic and stochastic flood inundation maps cannot be quantitatively compared. We show that the proposed simplified approach to flood risk assessment can be applied even when breaching of the embankment occurs, with the condition that the flooded area is small enough to be filled rapidly.

\section{Introduction}

Two different general approaches are used in modelling environmental processes, deterministic and stochastic. The uncertainty of model parameters related to errors in observations of process variables, such as flows, water levels, rainfall and temperature is neglected in the first approach, whilst in the second approach some sources of uncertainty are taken into account, which allows the influence of observation errors on model predictions to be assessed. Physical processes may be described by models based on mass and energy, or momentum balance in both the aforementioned approaches. These types of models are described by a set of nonlinear differential equations, which due to the complex initial and boundary conditions and nonlinearity of the relationship between process variables do not have analytical solutions, but instead are solved using numerical methods, with simplifying assumptions regarding model structure. One example is the model of flow in an open channel described by Saint Venant equations. Most of the popular numerical schemes 
for flood inundation modelling as, for example, MIKE11 (http://www.dhigroup.com), ISIS (http://www.halcrow.com) or HEC-RAS UNET (Barkau, 1993), are based on the Saint Venant kinematic flow approximation. It should be noted that 2-D and 3-D hydrodynamic models can better describe complex flow in rivers than 1-D models; however, they are less frequently applied due to the limited amount of available data required for model calibration and validation. As a result they are never used for routine flood risk mapping.

Flow routing models (1-D, 2-D, and 3-D) require a knowledge of the roughness parameters and geometry of the channel and floodplains. This information is usually obtained from field measurements. Due to measurement errors and the unavoidable interpolation and approximations related to numerical representation of the flow processes and numerical errors, the estimated values of water levels in the river are very uncertain (Grayson et al., 1992; Horritt, 2000; Hankin et al., 2001). The fundamental problem is how this issue can be handled in a flood risk analysis.

The most commonly applied, and that recommended in Poland, method for deriving flood risk maps is based on the deterministic simulation of a 1-D flow routing model for flood waves of a specified frequency of occurrence (Radczuk et al., 2001; Kitkowski and Nieznanski, 2009) to derive maps of flood inundation extent. In that approach the uncertainties related to observations, boundary conditions, and model parameter uncertainty are neglected.

However, the uncertainty is significant in flood inundation mapping. Romanowicz et al. (2010) presented a comparison of deterministic and probabilistic flood extent maps using the HEC-RAS UNET unsteady state flow model (Barkau, 1993) applied to the lowland River Narew in north-eastern Poland. There is a substantial difference between the results obtained using both approaches. Di Baldassarre et al. (2010) presented a critical discussion of deterministic and probabilistic approaches to flood risk assessment. In their paper the uncertainty of the 1-in-100 yr event was taken into account by sampling from the 1-in-100 yr discharge within a $\pm 15 \%$ range, assuming an equal probability for each sample. The authors performed a qualitative (image based) comparison of the derived flood inundation maps, assuming that flow model parameters do not depend on the input flood wave.

Our paper deals with the problem of uncertainty impact on flood inundation mapping. In order to maximise the usefulness of probabilistic flood risk assessment we present a simplified methodology that makes the assessment feasible in practice. For this reason we have applied a 1-D rather than 2-D model which could be more suitable for flood inundation modelling (in particular in urban areas). Additionally, a stochastic approach requires hundred of thousands of computations of a flow model, which must take enormous computer time for a single case study when a 2-D model is used. Moreover, Horritt and Bates (2002) and Chatterjee et al. (2008) report that under specific conditions, a 1-D model provides a similar estimate of inundation extent to a 2-D model, even in the case of a large floodplain. Experience shows that for a large, lowland river the time of flood wave passage is relatively long (over $100 \mathrm{~h}$ for Warsaw). Therefore, in order to decrease computation times, we propose in this paper an application of a steady state flow routing model based on HECRAS (http://www.hec.usace.army.mil) for a maximum flood wave of a given probability of annual exceedance. Flow is used as an input and water levels are the model output. We test the model using a new case study, the Warsaw reach of the River Vistula, which is relatively short with small water level gradients. The range of applicability of this simplifying assumption is given by Romanowicz et al. (2013b), where the steady state flow assumptions for the Warsaw reach were tested for river bank breaching conditions. That work has shown that a steady state 1-D model gives acceptable approximations to the unsteady state model in the case studied.

Three different types of uncertainty related to inundation mapping are discussed: flow model parametric uncertainty, uncertainty related to flood quantiles of 1 in $N$ yr flood and the uncertainty of the maximum annual flow. We do not take into account the uncertainty related to rating curve approximations. In order to estimate the uncertainty of simulated water levels in the river related to parameter and structural errors we apply an informal Bayesian uncertainty estimation procedure (Smith et al., 2008), which closely follows the pseudo-Bayesian generalised likelihood uncertainty estimation (GLUE) of Beven and Binley (1992). This approach is suitable for the uncertainty analysis of complex, multiparameter flow routing models and was successfully applied to many flow-routing problems, e.g. Romanowicz and Beven (2003) and Di Baldassarre et al. (2010). The method is not statistically efficient but easy to apply. It consists of Monte Carlo forward simulations of the model for an assumed prior distribution of model parameters. As the MC approach requires multiple simulations of the model, it is restricted to relatively simple models. However, it has been successfully applied to both lumped and distributed environmental models.

We apply flood frequency analysis (FFA) to observed annual maximum discharges and derive a theoretical distribution using the maximum likelihood approach. The uncertainty related to the design flood, understood to be a 1-in$N$ yr flow, is estimated from the theoretical distribution uncertainty limits.

In order to derive global uncertainty of inundation extent conditioned on the design flood, the probabilities related to the design flood and flow model uncertainties should be integrated (Krzysztofowicz, 2002). In the case of independence, both probabilities can be multiplied. However, roughness parameters depend on flood wave (Fread, 1992; Romanowicz and Beven, 2003; Yen, 2002). Therefore in the present paper we take into account the dependence of roughness coefficients on discharge. When that relationship is not taken into account, the input flood wave uncertainty and flow model parameter uncertainty are implicitly assumed to be 
independent. The roughness coefficients are parameterised on the basis of optimised values for 27 observed historical flood peaks from the period 1984-2010. It has to be noted that such a dependency has been applied in an uncertainty analysis of flood inundation for the first time.

As a result the total probability distribution of an inundation is obtained. A comparison between the probabilistic and deterministic formulations of the problem made on such a basis allows us to raise the question of how the risk related to the river discharge is affected by the model uncertainty. To our knowledge, in recent times only Aronica et al. (2012) have dealt with a similar problem, although they assumed the independence of roughness coefficients from flows. Apart from the probability maps conditioned on a design flood, a marginal probability of flood inundation is also derived as a result of integration over the flow of a joint probability of flow magnitude and maximum water levels. For the short, lowland river reach a relationship between inundation extent area and discharge is well defined and can be treated as a measure of the small-scale nonlinearity of flow transformation processes. Moreover, when combined with the uncertainty assessment of both flood-wave and inundation area predictions resulting from model parameter uncertainty, and the flood damage assessment, the relationship can be used as a measure of uncertainty of the costs of flooding in the area.

The main aims of this work and its main novelty are (i) introducing a new, simplified approach to probabilistic flood extent mapping that takes into account the dependence of flow model parameters on the design flood wave; (ii) the analysis of the influence of model simplifications (an application of a stochastic steady state flow routing model) on the probability of inundation extent; (iii) the derivation of the uncertainty of inundation extent conditioned on the design flood taking into account the dependence of roughness coefficients on flow; (iv) a quantitative comparison of deterministic flood extent maps derived using a single realisation of a flow routing model with those derived using a stochastic approach; and (v) a cumulative assessment of flood extent using a relationship between the area of flood extent and flow.

In Sect. 2 we present the methodology, including a statement of the problem and deterministic and stochastic approaches to flood risk assessment. The case study, the $36 \mathrm{~km}$ long Warsaw reach, is described in Sect. 3. Section 4 gives a short description of the approach used to derive the uncertainty of a flood wave with a given return period. Section 5 presents the parameterisation of roughness coefficients of a flow routing model and discusses the applicability of a steady state solution. Section 6 gives a comparison of the deterministic and stochastic approaches to the derivation of flood extent maps. Conclusions are given in Sect. 7.

\section{Methods}

\subsection{Statement of a problem in probabilistic flood extent mapping}

The problem of the derivation of a flood extent map for the purpose of flood risk assessment can be formulated as a transformation of the flood wave of a given return period by a flow routing model and the estimation of the flood inundation extent. In the stochastic approach, both flood wave and model parameters are assumed to be uncertain, whilst in the deterministic approach a single realisation of that transformation is regarded as a flood risk map. Flood extent maps are usually obtained from the interpolation of water levels along the river reach. Therefore it is convenient to state the problem in the form of maximum water level predictions along cross sections of the modelled river reach.

In order to compare the approaches, we start with a formulation of the problem in the Bayesian framework, following the approach presented by Tarantola (1987). First, we introduce a forward problem, that in this case is a transformation of a flood wave into the maximum set of water levels along the cross sections:

$\boldsymbol{Z}_{\max }=G(\boldsymbol{m}, Q)$,

where $\boldsymbol{Z}_{\max }$ denotes the vector of maximum water levels, $G$ denotes a transformation operator, $\boldsymbol{m}$ denotes a vector of model parameters and $Q$ is the input flow rate.

The inverse problem is posed in the context of an observation equation, which requires the choice of observation variables. That choice is usually dictated by the observation availability but should be done explicitly. Depending on the choice of the observed output, different criteria will be used during model evaluation.

When a Bayesian approach is used (Box and Tiao, 1992), we assume that the parameters and flow in Eq. (1) are random and that information on those variables can be presented in the form of a distribution function. The Bayes formulation of our inverse problem has the form (Tarantola, 1987)

$f(\boldsymbol{m}, Q \mid z)=\frac{f_{0}(\boldsymbol{m}, Q) M(z \mid \boldsymbol{m}, Q)}{f_{n}(z)}$,

where $z$ denotes the observation vector (including both input and output observation), $f_{0}(\boldsymbol{m}, Q)$ denote the prior information on input flow and model parameters, $f_{n}(z)$ is a scaling factor, and $M(z \mid \boldsymbol{m}, Q)$ represents the theoretical information on the relationship between $z$ and $(\boldsymbol{m}, Q)$, obtained from the forward modelling (Eq. 1). Flood extent modelling for the purpose of flood risk assessment is usually related to the maximum annual flow, whose distribution can be estimated following a FFA (see Sect. 4). We assume that the predicted 1-in- $N$ yr design flood flow $Q$ has a log-normal distribution with a mean value $Q^{*}$ and a variance $\sigma^{*}$ derived from the observed maximum annual flow records (see Sect. 4). 
The solution of the inverse problem formulated by (Eq. 2) gives the information required to derive the predictive probability of maximum water levels corresponding to the 1-in$N$ yr annual maximum flow (Box and Tiao, 1992):

$P\left(\boldsymbol{Z}_{\max }<y \mid z, Q^{*}\right)=$

$\sum_{\boldsymbol{m}} \sum_{Q \in \Omega^{*}} P\left(G(\boldsymbol{m}, Q)<y \mid \boldsymbol{m}, Q^{*}, \boldsymbol{z}\right) f\left(Q \mid Q^{*}\right) f(\boldsymbol{m}, Q \mid \boldsymbol{z})$,

where $Q^{*}$ denotes the 1-in- $N$ yr maximum annual flow, $f\left(Q \mid Q^{*}\right)$ is $N\left(Q^{*}, \sigma^{*}\right)$, and $\Omega^{*} \sim N\left(Q^{*}, \sigma^{*}\right)$. From Eq. (3) the quantiles of maximum water levels corresponding to the assumed probability of flooding can be derived, thus allowing for maps of the probability of flooding with a given return period to be estimated. When the risk of flooding is of concern we need to derive the marginal predictive probability of maximum water levels and the flow probability should be integrated. Assuming that the distribution of maximum annual flows can be approximated by a theoretical distribution (see Sect. 4), the marginal probability of maximum water levels has the form (Box and Tiao, 1992)

$$
\begin{aligned}
& P\left(\boldsymbol{Z}_{\max }<y \mid z\right)= \\
& \sum_{\boldsymbol{m}} \sum_{Q \epsilon \Omega} P(G(\boldsymbol{m}, Q)<y \mid \boldsymbol{m}, Q, z) f(\boldsymbol{m}, Q \mid z) f(Q),
\end{aligned}
$$

where $f(Q)$ denotes the distribution of maximum annual flow values derived in Sect. $4, \Omega \sim L N(\mu, \sigma)$. The marginal probability $P($.) gives information on the total probability of flooding in the area.

The problem of the derivation of flood inundation extent can be formulated as the transformation of the flood wave of a given return period into the inundation extent. In a deterministic approach, we assume that $(\boldsymbol{m}, Q)$ are deterministic and therefore the probability of $(\boldsymbol{m}, Q)$ would always be 1 . If the flow routing model, used to transform the input flow into the inundation extent, was linear, in respect to both flow and model parameters, the inundation extent obtained using a 1-in- $N$ yr input flow (so-called design flood) would give a 1 -in- $N$ yr inundation extent, which is the aim of the flood risk mapping. In mathematical terms, only for a linear flow routing model can the operator of expectation move from in front of the operation into the variables. This requirement might be written in the following general form:

$E(G(\boldsymbol{m}, Q))=G(E(\boldsymbol{m}), E(Q))$,

where $G(\boldsymbol{m}, Q)$ is an operator (flow routing model) acting on the stochastic variables $(\boldsymbol{m}, Q)$ and $E()$ denotes the expectation.

As mentioned earlier, flood extent is derived by an interpolation from the maximum water levels predicted for the assumed design flood. Thus the transformation of the input flow into inundation extent is nonlinear with respect to both flow and model parameters. It depends on the channel and floodplain geometry, roughness coefficients and on the flood wave maximum discharge, which additionally undermines the linearity of the flood wave transformation problem.

The assumption of a deterministic approach would mean that we have as many probability maps as there are possible realisations of the flow routing model (for different parameter sets) and the answer to our problem would be not specified. In order for the assumption (Eq. 5) to be fulfilled, the operator $G$ should be linear. In fact, it would be sufficient if it was linear for the range of flows most likely to occur for the flood wave of a required return period.

In our case, this would require the relationship between flood extent area $A$ and water levels and input flow rate to be linear. This formulation also suggests a different approach to flood risk mapping. Instead of concentrating on spatial predictions, we can derive the relationship between flood extent and flow values with confidence limits and match them with similarly derived maps of the costs of flooding to obtain a cumulative assessment of flood risk.

The questions we want to answer are, what probability values can we assign to the deterministic flood inundation extent map and how would the deterministic maps differ from those where the uncertainty of the model parameterisation is taken into account? We shall compare the maps obtained only when the uncertainty of a flood wave with a specified return period is taken into account.

\subsection{Deterministic method of derivation of flood inundation extent used in practice}

Following the recommendations presented by Radczuk et al. (2001) and Kitkowski and Nieznanski (2009), the deterministic approach to the estimation of flood inundation extent consists of the following stages:

1. Development of a 1-D flow routing model (e.g. HECRAS or MIKE11) using available information about the river channel and floodplain geometry, taking into account existing engineering structures in the area affected by flow, e.g. bridges.

2. Deterministic calibration and validation of a 1-D flow model using the available water level observations.

3. Derivation of synthetic flow waves with a specified probability of annual exceedance (e.g. $p=0.01$ or $p=0.001$, equivalent to $100 \mathrm{yr}$ or $1000 \mathrm{yr}$ flood).

4. Estimation of flood inundation extent on the basis of 1-D model simulations for an assumed flood wave and a digital terrain model (DTM) for an area.

The derived flood inundation maps can be used to estimate the potential flood damage based on information on the number of inhabitants, the infrastructure and the land use in the catchment. 


\subsection{Stochastic approach to the derivation of flood inundation extent}

A stochastic approach to the derivation of flood extent maps that also takes into account the uncertainty of observations (including the initial and boundary conditions and the model parameters) consists of the following stages:

1. Development, calibration and validation of a deterministic 1-D flow routing model based on historical observations.

2. Generation of a priori distributions for the chosen parameters (roughness coefficients) and boundary and initial conditions using information obtained from the deterministic optimisation regarding the mean values and the parameter variance.

3. Stochastic simulation of the model using e.g. Latin hypercube sampling of a parameter space.

4. Bayesian conditioning of model predictions using available observations (a version of the GLUE methodology) to derive an a posteriori distribution of model parameters and predictive uncertainty of the model output.

5. Stochastic validation consisting of running the model for historical data different to those used during the calibration stage; the a posteriori distribution of the parameters obtained during the calibration stage is used to derive the a posteriori distribution of model predictions (e.g. maximum water levels at the analysed cross sections of the river reach).

6. Generation of ensembles of flood waves with a specified probability of exceedance (i.e. a probability of an event being greater or equal to a given value), corresponding to the uncertainty of the flood frequency curve derived for an input cross section of the model.

7. Multiple simulation of the 1-D flow routing model for randomly varying parameters, initial conditions (input ensemble) and random boundary conditions.

8. Estimation of a posteriori outputs from the model in the form of water levels at cross sections of the reach for flood waves of a specified exceedance probability and the derivation of maps of probabilities of maximum inundation.

\section{Description of the River Vistula case study}

The $36 \mathrm{~km}$ long Warsaw reach (Fig. 1) starts from the Jeziorka tributary and ends before the Vistula's tributary Narew. Due to its glacial past, the upper part of this reach forms the so-called "Warsaw corset", where the river valley width decreases rapidly from $7500 \mathrm{~m}$ at $507 \mathrm{~km}$ to $600 \mathrm{~m}$

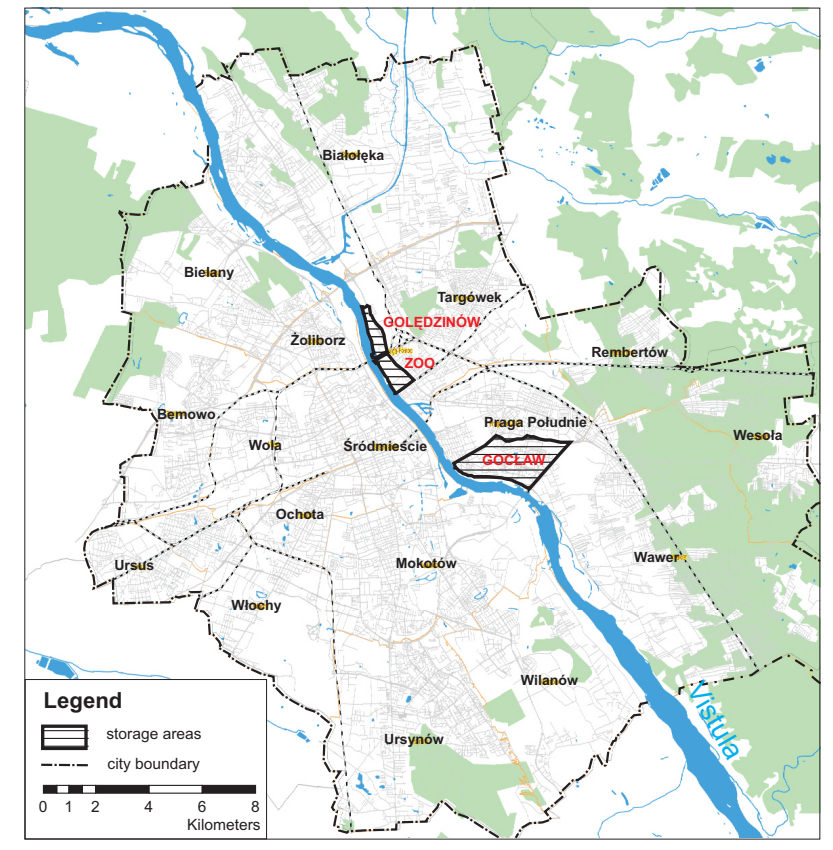

Fig. 1. Study area - Warsaw reach of the River Vistula - breaching test locations (Goclaw, ZOO, and Goledzinow).

in Warsaw $(514-516 \mathrm{~km})$. The mean annual discharge at the Nadwilanowka gauge is $573 \mathrm{~m}^{3} \mathrm{~s}^{-1}$. This part of the river valley is highly urbanised and embankment systems are situated on both river banks along the whole reach length. The floodplains consist mainly of a diverse vegetation cover and only small parts of the left bank are protected by solid cement constructions. From the flood protection point of view, the tree-rich habitats along the whole right bank might affect river flow due to increased resistance.

Low flows are regulated by a system of replying spurs, which also contributes to an increase of water levels during freshets. The character of the flood-endangered city areas is diverse along the reach. Generally the upstream parts of the reach are densely populated and downstream parts consist of a dispersed development; however, each part differs significantly. On the right bank large housing complexes exist in the direct neighbourhood of the embankments and such areas are considered to be especially endangered.

There have been only a few studies published on flood modelling of the Warsaw reach of the Vistula. Kuzniar (1997) estimated water surface levels for a $500 \mathrm{yr}$ flood event and compared it with historical observations. Hydroprojekt Warszawa developed a complex program of flood prevention for the middle Vistula, in which a 1-D steady state flow model was used to assess flood inundation zones (Hydroprojekt, 1999). Magnuszewski et al. (2009) applied a 2-D deterministic model to compute the inundation extent caused by embankment breaching at densely populated parts of the river valley. All these approaches are deterministic, so the 
estimated flood risk zones do not reflect the uncertainty of the model parameters and its boundary conditions.

The analysis of inundation extent is limited to three areas (Fig. 1): two smaller (ZOO and Goledzinow) and one larger (Goclaw). All are isolated and protected with embankments. Therefore these areas might be considered as storage zones for flood water, in the case of embankment failure or overtopping.

\section{Derivation of a design flood; FFA analysis for the Warsaw reach of the River Vistula}

Water resource management requires information on water availability in both short and long time horizons, locally and regionally. In particular, information on the maximum probable flow and its duration and timing is important for the design of water structures, such as embankment height, reservoir spillways and bridges. For this purpose a design flood is estimated. In the present paper we are interested solely in the derivation of the maximal discharge of the flood wave with a specified return period, used as an input to the steady state flow model.

Methods of derivation of maximum flows with a specified return period are based on fitting an analytical distribution to series of annual maximum observed flows. Due to the usually short length of available observations, the estimates are strongly biased (Strupczewski et al., 2002). The results of this procedure depend on the choice of an appropriate probabilistic distribution, uncertainty in estimated distribution parameter values, uncertainty in the river discharge data and the lack of stationarity of the observed time series (Yue et al., 2002; Strupczewski et al., 2007).

The FFA approach was applied to develop a theoretical distribution of maximum annual flows for the Warsaw reach of the River Vistula. The analysis was based on $90 \mathrm{yr}$ of observations from 1921 to 2010, the longest available homogeneous time series. It should be noted that available measurements span a much longer period, the gauging station in Warsaw having been set up in 1789. However, the previous records were mostly limited to water levels, and due to changes in the gauging station location and its datum, it is difficult to evaluate the rating curve and to calculate discharges.

In the first step of the analysis we tested statistically whether the data are independent, stationary, and homogeneous. The independence of data was tested by the WaldWolfowitz test, Kendall's test for stationarity, and homogeneity was tested by the Wilcox test. The empirical probability distribution was calculated in accordance with the Weibull formula. The nine most commonly used probability distributions (exponential, GEV, Gumbel, Weibull, log-normal, lognormal with three parameters, Gamma, Pearson type III, logPearson type III) were applied to describe maximum annual flow. The parameters of these distributions were estimated

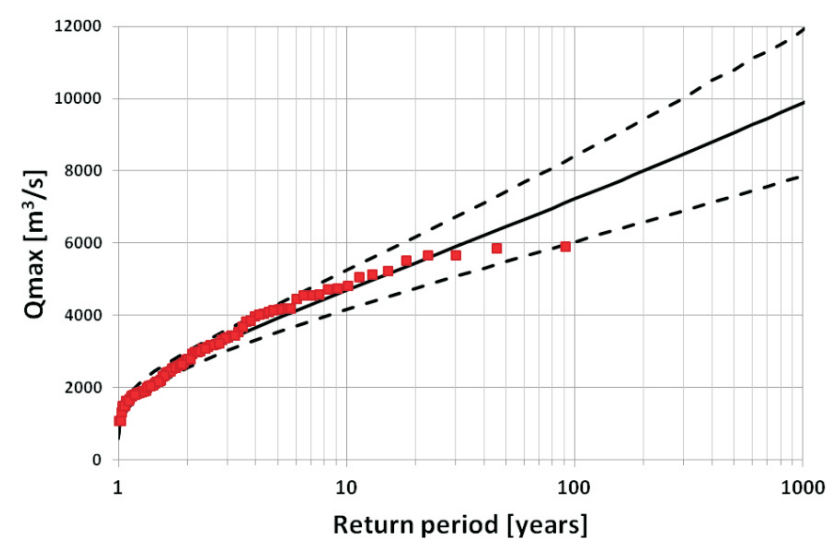

Fig. 2. Comparison of the empirical distribution with a twoparameter log-normal distribution estimated using the maximum likelihood method for the Warsaw reach; squares represent the empirical distribution, continuous line denotes the estimated theoretical distribution, dashed lines represent 0.95 confidence limits.

using four methods: maximum likelihood (MLM), moments $(\mathrm{MOM})$, probability weighted moments (PWM), and the distribution of the log-Pearson type III by a method recommended by the US Water Resources Council (WRC) in wellknown guidelines for flood frequency analysis, Bulletin 17B (USIACWD, 1982).

Standard statistical tests did not lead to the rejection of any distribution and on this basis it was difficult to determine the best. Four additional selection criteria were applied: Akaike information criterion and Bayesian information criterion (Akaike, 1974; Strupczewski et al., 2011), the average absolute deviation index (MADI) and the mean square deviation index (MSDI) (Mitosek et al., 2002). As a result, a two-parameter log-normal distribution (LN2), estimated by the method of maximum likelihood (MLM), was selected. The distribution together with the confidence limits and the observed annual maximum discharge values are shown in Fig. 2.

In the following sections the derived theoretical distribution of maximum annual flows is used to estimate quantiles of a 1-in- $N$ yr flow together with their uncertainty.

\section{Calibration and validation of the MSS model; introducing roughness coefficients dependent on flow}

\subsection{Matlab steady state model (MSS)}

The water levels were computed with a Matlab steady state flow model (MSS) developed according to the original HECRAS model description.

The algorithm was presented in detail by Brunner (2010). The model is based on the energy and continuity equations. The water resistance is described by the Manning equation. As in the original code, the flow is subdivided into separate 
units to take into account a non-uniform distribution of velocity within a cross section. Each cross section is divided into three zones: channel and left and right floodplains, for which different Manning coefficient values have to be specified. The reason for using the MSS model, rather than the original steady state HEC-RAS model, is a matter of convenience. Multiple Monte Carlo realisations require that the model programming interface is as transparent as possible and this can be easily achieved with the direct use of the code, written in the same environment as the MC runs.

A TIN digital terrain model from aerial imaging and 114 channel cross sections forms the basis of the representation of the river valley topography. Measurements of the channel were carried out by Falacinski et al. (2009), providing very useful information for this research. A DTM on a regular grid of $10 \mathrm{~m} \times 10 \mathrm{~m}$ resolution was prepared in order to integrate the elevation data. An evaluation of model functions from this type of elevation data gives similar advantages to using a finite element model, because it is possible to include the spatial diversity not only at cross sections but also between them. The upstream end of the river reach was placed at the Vistula inflow of the Jeziorka, situated along the southern border of Warsaw.

Inundation maps were obtained by projecting the computed water levels onto the 2-D grid, using DTM. A linear interpolation was applied to compute values between cross sections.

\subsection{Parameterisation of roughness coefficients of the MSS model on flow}

Various studies, such as Fread (1992) or more recent by De Doncker et al. (2009), show that the Manning roughness coefficient reveals a dependency on river discharge. The problem is complex and one possible explanation is given in the first paper, where this effect is linked to changes of vegetation along the river banks that are submerged. Usually the resistance grows with the rise of water level, but some rivers can show the opposite effect (Fread, 1992), in particular, when the increase of flow area within the bank is relatively large compared to the increase in the overbank flow area, as is typical of wide rivers. Figure 3 presents the dependence of Manning roughness coefficient on discharge for the Warsaw reach for historical floods.

The relationship was elaborated on the basis of optimal parameters computed for maximal annual inflow rates. The data period includes 27 events in the years 1984-2010. For each set of an inflow and water levels at a river gauge, a minimisation problem, in a form of sum of square residua of the model, was formulated and the optimisation was conducted using a simplex algorithm. The methodology is similar to that adopted by Domeneghetti et al. (2012).

The relationship shows a linear decrease of Manning coefficient with increase of flow values for the channel and right floodplain. The left floodplain roughness coefficients

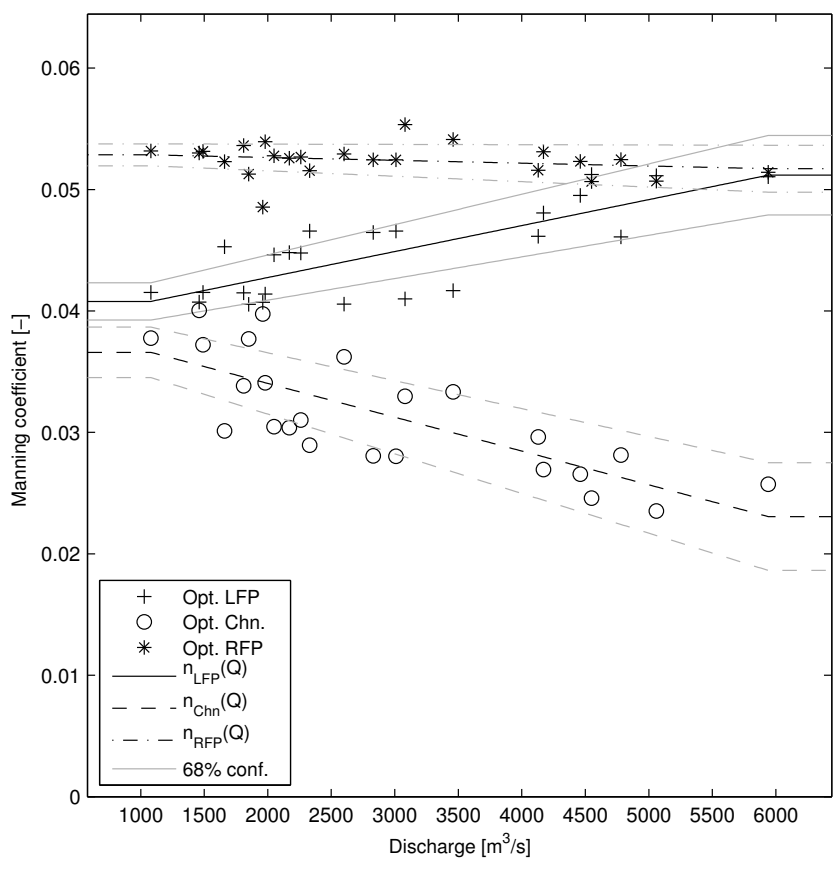

Fig. 3. Parameterisation of Manning roughness coefficients on discharge; circles, stars and crosses represent, respectively, channel, right-hand and left-hand floodplain roughness values obtained from the optimisation of the non-parameterised model; lines follow the function given by Eq. (6), fitted to the data; thick dashed lines show the linear fit and dashed thin lines present 0.68 confidence limits for the fit.

increase with the flow. The different behaviour of the right and left flood plain roughness coefficients may follow from their different geometry and differences in vegetation cover. The identification of the reasons for that behaviour is a complex task and requires further specific studies (Yen, 2002; Mugler et al., 2011).

We applied a linear parameterisation of the relationship between roughness coefficients and the flow. The parameterisation equation of the Manning coefficient $n$ for floodplains and channel has the form:

$n=\left\{\begin{array}{lll}a Q_{1}+b, & \text { if } & Q \leq Q_{1}, \\ a Q+b, & \text { if } & Q_{1}>Q>Q_{2}, \\ a Q_{2}+b, & \text { if } & Q_{2} \geq Q,\end{array}\right.$

where $n$ is the Manning coefficient as a function of a flow rate $Q ; Q_{1}$ and $Q_{2}$ denote the upper and lower bounds of a linear model. The $Q_{1}$ and $Q_{2}$ bounds were introduced to avoid extrapolation into discharge ranges not included in a calibration data set. In this case it was the minimum and maximum of an annual maximal flow. The results of the parameterisation are shown in Fig. 3. For the purpose of uncertainty estimation the uniform sampling of the parameter space was assumed, with parameter ranges given in Table 1 and the mean values equal to optimum (fitted) parameter values. 
Table 1. Parameter ranges used in Monte Carlo simulations; $a_{\mathrm{lfp}}, a_{\mathrm{chn}}, a_{\mathrm{rfp}}, b_{\mathrm{lfp}}, b_{\mathrm{chn}}, b_{\mathrm{rfp}}$ stand for $a$ and $b$ coefficients, given in Eq. (6), for left floodplain, channel and right floodplain, respectively.

\begin{tabular}{lrr}
\hline Parameter & Lower band & Upper band \\
\hline$a_{\mathrm{lfp}} \times 10^{-5}$ & 0.0528 & 0.5003 \\
$a_{\mathrm{chn}} \times 10^{-5}$ & -0.4966 & 0.1099 \\
$a_{\mathrm{rfp}} \times 10^{-5}$ & -0.1184 & 0.1456 \\
$b_{\mathrm{lfp}}$ & 0.0333 & 0.0476 \\
$b_{\mathrm{chn}}$ & 0.0326 & 0.0520 \\
$b_{\mathrm{rfp}}$ & 0.0501 & 0.0585 \\
\hline
\end{tabular}

\subsection{Calibration and validation of the MSS model}

At the model calibration stage, our goal was to obtain a robust solution. We achieved this by performing a parameter estimation for a $25 \mathrm{yr}$ observation period using the informal Bayesian uncertainty estimation procedure (Smith et al., 2008). At the model calibration stage we took into account the uncertainty related to model parameters, neglecting the uncertainty related to flow observations. The model parameters describing the parameterisation of the roughness coefficients (Eq. 6) were sampled uniformly 2000 times. Parameter ranges were selected following the results of the deterministic optimisation routine and are given in Table 1. Following a standard Bayesian procedure, the posterior distribution of the model parameters was obtained using Eq. (2) and input flows assumed to have known deterministic values, corresponding to historical flows.

In this way the parameter values that give superior results are weighted higher than those giving an inferior performance. The same weights are used for the estimation of the uncertainty of model predictions at the validation stage. The results depend on the choice of prior parameter sampling and the choice of evaluation criteria. Romanowicz et al. (1994) showed that the method is equivalent to the formal Bayesian approach when specific assumptions regarding the modelling error are fulfilled. However, this often requires introducing the transformation of the modelling errors and increases the number of unknown parameters and, in consequence, the uncertainty of model predictions. The other method commonly used in statistics is inflation of the modelling error variance to account for its unknown structure and being non-additive (Romanowicz and Beven, 2006). A similar approach was applied by Werner (2004) and Blasone et al. (2008).

The calibration data consisted of annual maximum water stage and discharge records for the 1984-2009 period for the Warsaw gauging station. The validation was performed against water surface elevation for the flood event in June 2010, with the peak discharge of $5898 \mathrm{~m}^{3} \mathrm{~s}^{-1}$.

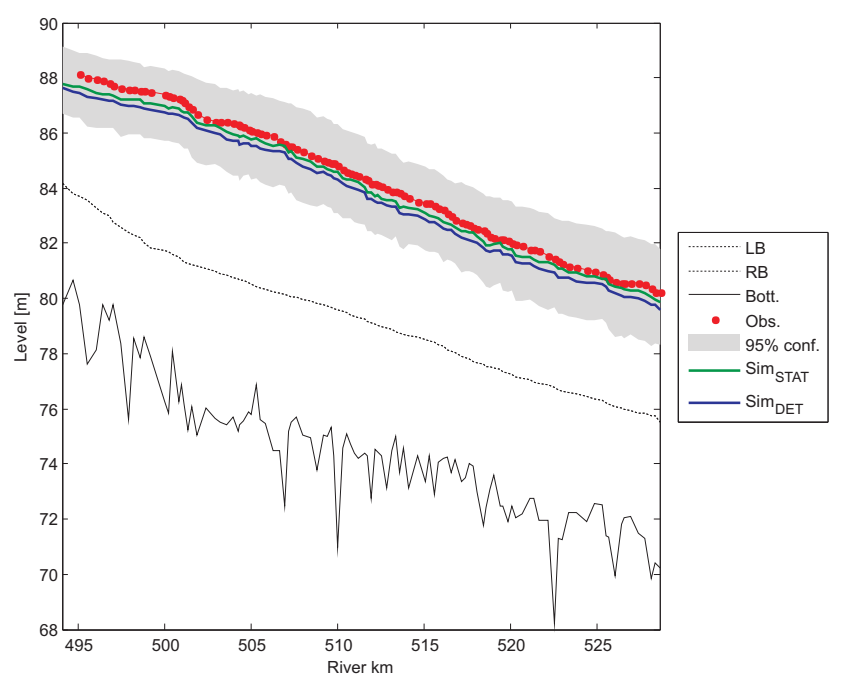

Fig. 4. Validation of the MSS model on the 2010 flood of the Warsaw reach. The observations are shown by red dots, median predictions obtained from the stochastic approach are shown by a green line, the deterministic solution is shown by the dashed blue line; grey shaded area shows the 0.95 confidence limits, the black continuous line shows the bottom of the river channel and the left and right bank heights are depicted by a dashed line.

The model validation results are presented in Fig. 4. The observations are shown by red dots, median predictions obtained from the stochastic approach by a green line and the deterministic solution by the dashed blue line. The grey shaded area shows the 0.95 confidence limits. The black continuous line denotes the bottom of the river channel and the left and right banks heights are depicted by a dashed line. The validation results reveal that the best parameter sets obtained from a deterministic solution give larger errors than a statistical solution, corresponding to the median of the model predictions.

\subsection{Test of the steady state flow assumptions for breaching conditions}

As mentioned before, in order to speed up the computations of the flow routing model, and make the stochastic approach less computationally demanding, it was decided to use a steady state flow - MSS model. Steady state flow is a special case of unsteady flow. Both problems can be solved only approximately, using numerical methods. A comparison of steady and unsteady flow solutions was presented by Franz and Melching (1996), who summarised the differences using the principle of conservation of momentum. From the governing equations presented by them it follows that a steady flow solution approximates that of an unsteady flow when the variation of flow and cross-sectional area with time is small compared to the variation of these variables with distance. The Warsaw reach is situated in the middle of a plain. The 
gradients are moderate and the variability of flow at the maximum relatively small. The assumption of steady state flow is challenged when breaching of the embankment occurs.

The validity of this assumption was tested by Romanowicz et al. (2013b), where a number of breaching scenarios were analysed. In general, three different widths of breaching, $50 \mathrm{~m}, 100 \mathrm{~m}$ and $150 \mathrm{~m}$ (Wierzbicki et al., 2013), at locations being considered in this study, i.e. Goclaw, ZOO and Goledzinow, situated on the right-hand side of the river, were analysed (Fig. 1). Each breach was located at the upper end of a storage area with the forming time set to $6 \mathrm{~h}$ with a constant velocity. The analysis was performed with the full (unsteady) HEC-RAS model (http://www.hec.usace.army.mil) for the historical 2010 flood wave. The resulting water levels were projected to the 2-D inundation extent using DTM. The assessment shows that in the case of the ZOO and Goledzinow locations, because of relatively small capacity, filling up the areas up to channel water level is rapid enough for its impact on river discharge to be neglected. The computed decrease of maximum water stages is below $4 \mathrm{~cm}$, significantly below model accuracy. However this it is not the case for the Goclaw area. Because of the significant capacity, the predicted impact of breaching at this site would lead to a $19-25 \mathrm{~cm}$ decrease of water levels along the river reach.

The test results indicate that the filling of two smaller breached areas is rapid enough to allow for the supply of flood water during the whole period of the passage of the flood wave along the Warsaw reach (about 3.5 days). Therefore this test shows that neglecting the weir-type flow between channel and flooded areas is justified when the breaching areas are small (ZOO and Goledzinow). This is also a justification for the application of a 1-D instead of a 2-D model.

In this paper we also compared the deterministic inundation maps for the ZOO area using the MSS and HEC-RAS unsteady flow models. The results show very small differences (Fig. 5).

\section{Comparison of the results and discussion}

In this section we present an application of the MSS model for the 1-in-100 yr flood event using a stochastic approach. During the MC simulation of the model we used the same sample for the roughness parameters as during the calibration stage, with parameter ranges given in Table 1 . In order to assess the influence of the input uncertainty on the flood extent estimates, 200 quantiles were generated for a 1-in-100 yr flood, assuming a normal distribution of quantile errors.

Following the procedure for the derivation of stochastic flood extent maps given in Sect. 2.3, stages 1-5 correspond to the derivation of a posteriori distributions of the model parameters and they constitute the stochastic development of the first two stages of the deterministic approach presented in Sect. 2.2. Stage 6 is equivalent to stage 3 of the deterministic approach, and stages 7 and 8 constitute the

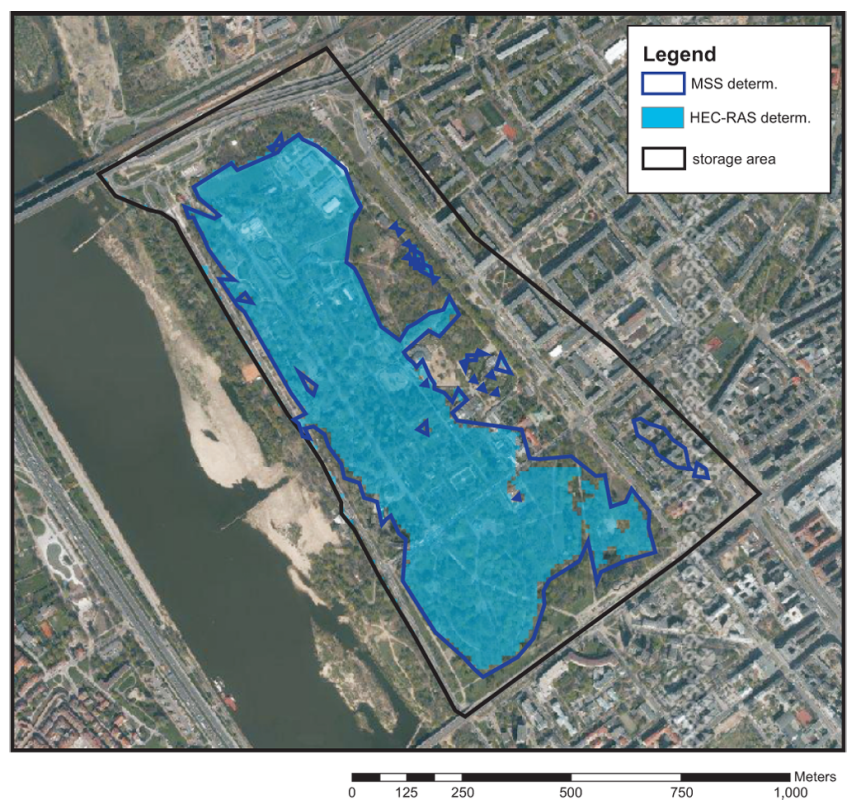

Fig. 5. Comparison of MSS and HEC-RAS unsteady flow inundation area for $\mathrm{ZOO}$.

stochastic development of the fourth stage of the deterministic approach. A more detailed description of all the stages of the stochastic approach can be found in Romanowicz et al. (2010). We shall discuss certain aspects of the approach presented where necessary changes were made due to the specific nature of the problem.

In order to compare the flood extent estimates obtained by deterministic and stochastic approaches, three different embankment breach scenarios were simulated. These correspond to the scenarios tested in Sect. 5.4, namely, ZOO, Goledzinow and Goclaw. They differ in the extent of the inundation area. The fourth scenario analysed assumes no breaching. The Goclaw area, for which a steady flow assumption was not confirmed, is given here for comparison.

The results of the deterministic and stochastic approaches for all scenarios, given in the form of a marginal cumulative probability of flood inundation extent, are presented in Fig. 6. The deterministic estimates of flood inundation extent for the flooded areas due to breaching are different to the estimates with parametric and input uncertainty taken into account. However, as might be expected, the in-channel flow probabilities of flood extent do not differ much (Fig. 6d). The flood extent areas obtained by the deterministic approach are shown by black dashed lines in Fig. 6. As this map results from a single realisation of a flow model for a 1-in$100 \mathrm{yr}$ flow, it does not have an uncertainty assigned. Goclaw has the largest inundation area, whilst ZOO and Goledzinow are smaller and comparable in size. Each of the cumulative density functions (cdfs) of inundation extent for the embankment breach scenarios show a complex, multimodal shape for the Goclaw area, apart from the no-breach 

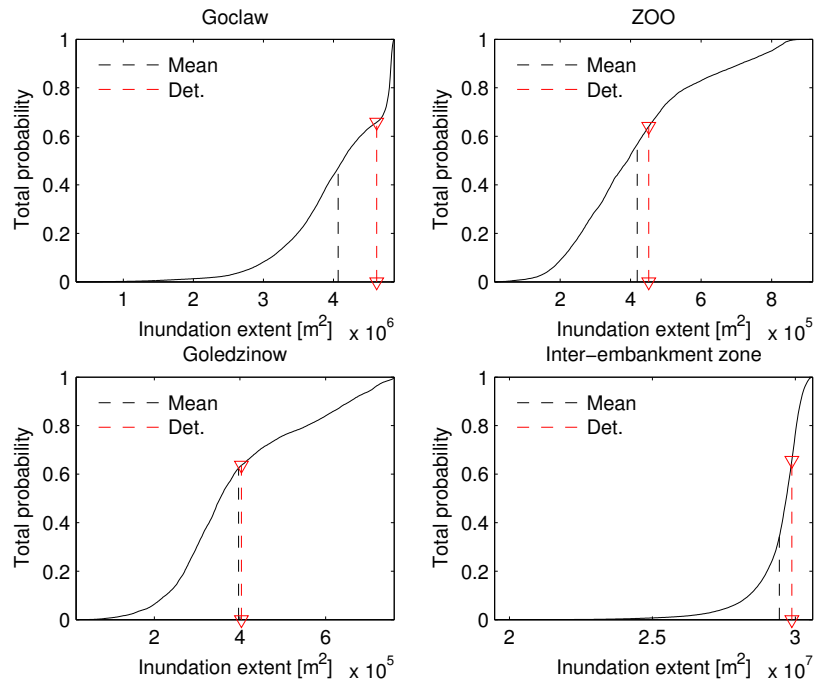

Fig. 6. Comparison of flood inundation extent for a 1-in-100 yr flow for four scenarios: (a) Goclaw; (b) ZOO; (c) Goledzinow; (d) inbank zone; perpendicular red dashed lines represent simulated deterministic inundation extent. Mean stochastic values are shown by black dashed lines.

scenario, which has a single mode. The multi-modality follows from the input flood wave uncertainty transformed by a non-linear flood inundation-water level relationship. Accordingly, the in-bank scenario shows that the transformation is close to linear. This means that the deterministic model predictions would be similar to the stochastic predictions for the in-channel steady state flow for the Warsaw reach. For the other scenarios, the deterministic solutions are located above the cdf median. These results show that the complexity of the transformation of input and parametric uncertainty through the nonlinear relationship between inflow and inundation extent in the embankment breaching conditions cannot be depicted by a deterministic approach.

As mentioned in Sect. 2, the estimates of maximum water level quantiles at the cross sections along the river reach can be used to derive probability maps of inundation extent. The map of probability of flooding due to breaching of the embankment in the ZOO area is shown in Fig. 7. The deterministic boundaries of inundation extent are shown by a solid blue line. The deterministic and stochastic maps cannot be directly compared. In order to present some sort of comparison, we assumed that the deterministic map represents water levels with a probability of exceedance of 0.5 . This assumption would be true if the transformation (Eq. 5) was linear. With this assumption, the deterministic map shows a larger flood extent than the stochastic. This is different to the results obtained for the Narew reach (Romanowicz et al., 2010), where an underestimation of the deterministic map was apparent.

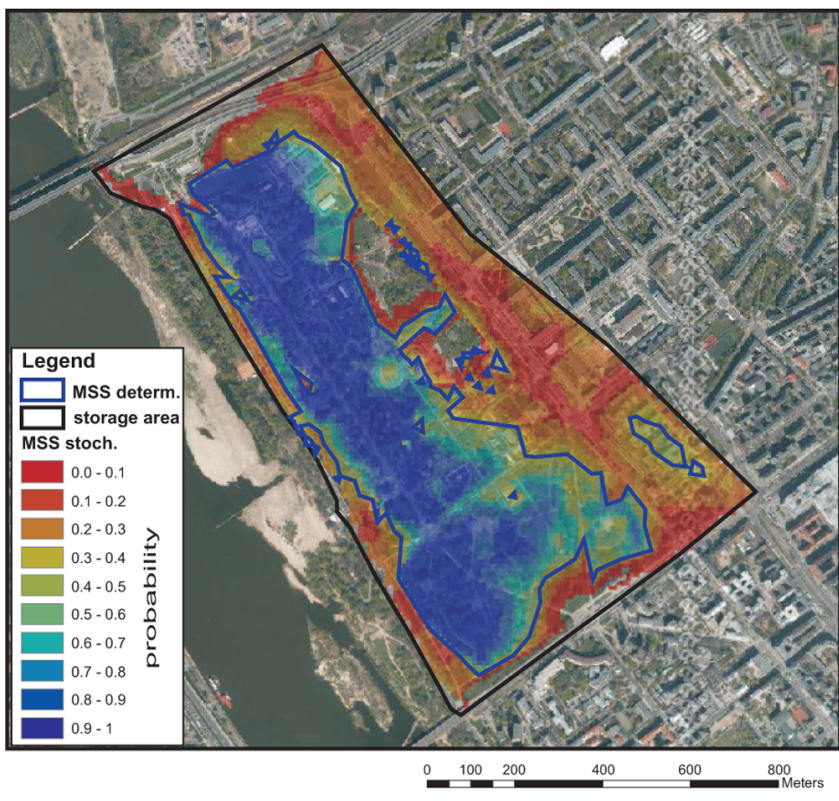

Fig. 7. The map of the probability of inundation extent for the $\mathrm{ZOO}$ area with superimposed deterministic boundaries.

The methodology for the derivation of distributions of flood extent of a specified probability following the deterministic approach (Kitkowski and Nieznanski, 2009) is obviously much simpler than the statistical approach. However, when comparing the results, one should remember that they represent totally different values.

Figure 8 presents the cdfs of water levels at four cross sections $(1,40,80$ and 114) of the MSS model for a 1-in- $100 \mathrm{yr}$ flood event, taking into account an estimated uncertainty of the model. The four panels in Fig. 8 illustrate that the flood transformation generated by a deterministic approach differs from the solution obtained by a stochastic approach. Therefore, the flood extent at those cross sections, derived using a deterministic approach, does not represent a maximum probable inundation extent nor an extent that has a 0.5 probability of annual exceedance nor mean value. Moreover, each analysed river cross section will be characterised by a different cumulative distribution of the probable water levels and a different relationship to the deterministically derived water levels. Equation (1) can be written in the form of a dependence of inundation area $(A)$ and input flow as an inundation extent is obtained by the interpolation of maximum water levels over the DTM of the area. Applying the posterior distribution of parameter and input flow rate values obtained from Eq. (2) we can present the prediction of inundation area as a function of input flow $Q$. The derived relationship for the $\mathrm{ZOO}$ area (Fig. 9) shows that uncertainty related to model parameters varies with the value of $Q$. This relationship can be parameterised and applied in flood risk assessment studies. 

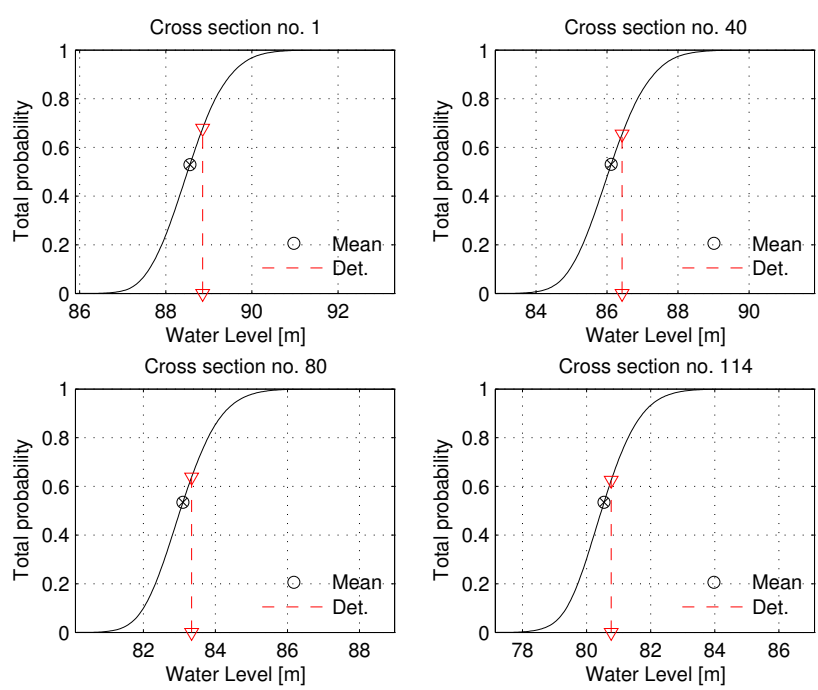

Fig. 8. The marginal cumulative probability density function of water levels at the MSS model cross sections (1, 40, 80 and 114) located along the Warsaw reach of the River Vistula for a 1-in-100 yr flood event flood event; solid lines show the distribution of water levels obtained using the GLUE framework; red dashed lines show the deterministic solution; mean values of water levels are shown by black circles.

In Fig. 9 the dashed perpendicular lines denote water level values obtained using a deterministic approach. This figure gives us a different way of conditioning the model parameters, and would be very easily applied when the conditioning is done using satellite inundation images. The dot-dash lines represent the 1 -in-100 yr flow, together with 0.95 confidence limits and corresponding 1-in-100 yr inundation extent. If the inundation area can be related to flood damage, the above curve would give estimates of the risk together with confidence limits. The approach seems to be simple and it can be applied to either 1-D or 2-D flow routing models. Figure 9 shows that the uncertainty of the relationship between inundation extent and discharge is very large and grows with the discharge value. Those wide uncertainty ranges result from the uncertainty of the design flood integrated with model parametric uncertainty. It indicates that further work towards decreasing that uncertainty is required.

\section{Conclusions}

This study has shown that the deterministic approach used for the derivation of risk of flooding does not answer the question as to what is the probability of inundation extent. The results indicate that there is no unique representation of the deterministic flood inundation map because the probability of inundation extent derived from a single realisation of the set of all possibilities is not defined. Depending on what probability is assumed for the map, a different flood risk will

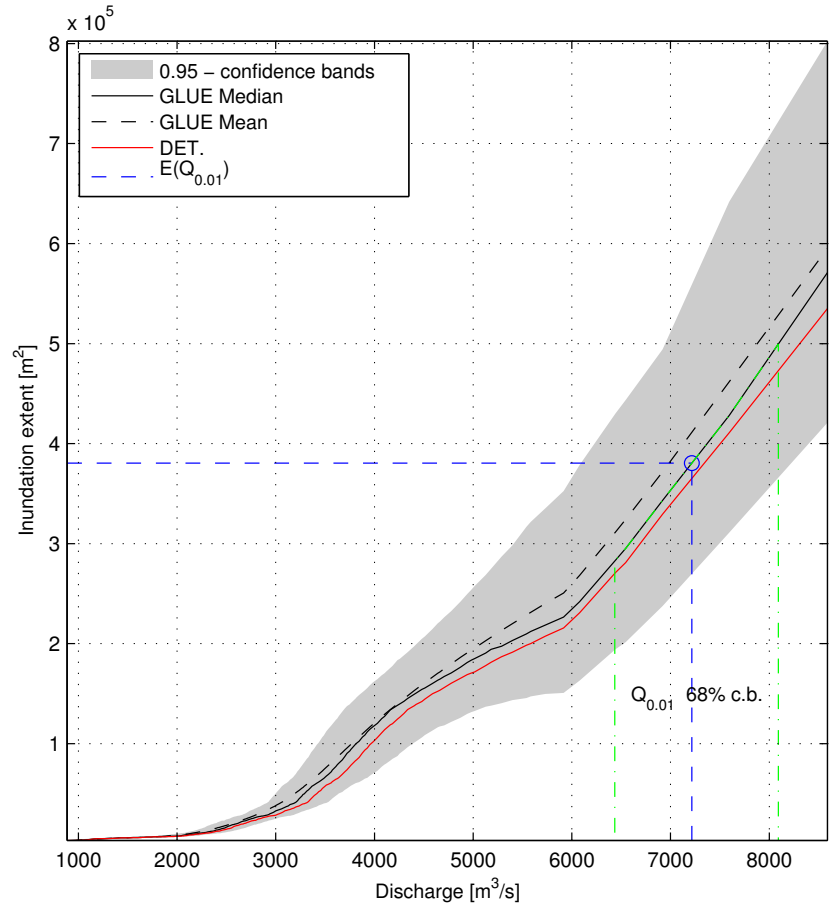

Fig. 9. Relationship between the inundation extent and the input flow rate for the ZOO area. Continuous red line denotes the deterministic solution, black continuous line denotes the median, black dashed line denotes the mean and gray shaded area denotes 0.95 confidence bands; blue dashed lines show a 1-in-100 yr flow and corresponding inundation extent value; green dashed lines denote 0.68 confidence limits.

be derived. Therefore one cannot assert that the uncertainty related to flooding is small in comparison with the uncertainty related to the potential losses without estimating that uncertainty.

Maps of the probability of flood extent are required for the derivation of flood risk, as defined by multiplying the probability of the event and the damage caused by that event (Radczuk et al., 2001; Di Baldassarre et al., 2010). In the case of deterministic maps, a question arises as to the probability they represent.

The task of performing a stochastic approach to flood risk assessment is too computer-demanding to be practically feasible. In this study we tested a simplified approach consisting of the application of a steady state flow model and we have shown that this approach gives a reasonable approximation to the unsteady state solution for the Warsaw reach for two out of three tested breaching conditions. The dependence of roughness coefficients on flow has been taken into account via the parameterisation of a 1-D steady state flow routing model on flow. This allowed the conditioning of flow routing model predictions on the design flood. This dependence can be also applied in a 2-D model and further work is planned in that direction. 
A new way of flood risk mapping is suggested by the dependence of the flood extent area on flow. The uncertainty of this dependence increases with flow values.

Acknowledgements. This work was financed by the project "Stochastic flood forecasting system (The River Vistula reach from Zawichost to Warsaw)" carried out by the IGF PAN for the National Science Centre (contract no. 2011/01/B/ST10/06866). The flow data were provided by the Institute of Meteorology and Water Management (IMGW), Poland. We thank three anonymous reviewers for their constructive comments, which helped us to improve the manuscript.

Edited by: A. Loukas

Reviewed by: three anonymous referees

\section{References}

Akaike, H.: A new look at the statistical model identification, IEEE T. Automat. Contr., 19, 716-723, doi:10.1109/TAC.1974.1100705, 1974.

Aronica, G. T., Candela, A., Fabio, P., and Santoro, M.: Estimation of flood inundation probabilities using global hazard indexes based on hydrodynamic variables, Phys. Chem. Earth, Parts A/B/C, 42, 119-129, doi:10.1016/j.pce.2011.04.001, 2012.

Barkau, R. L.: UNET one-dimensional flow through a full network of open channels user's manual version 2.1, Publication CPD-66, US Army Corps of Engineers Davis CA, Hydrologic Engineering Center, Washington, DC, USA, 1993.

Beven, K. J. and Binley, A.: The future of distributed models: model calibration and uncertainty prediction, Hydrol. Process., 6, 279298, doi:10.1002/hyp.3360060305, 1992.

Blasone, R. S., Madsen, H., and Rosbjerg, D.: Uncertainty assessment of integrated distributed hydrological models using GLUE with Markov Chain Monte Carlo sampling, J. Hydrol., 353, 1832, doi:10.1016/j.jhydrol.2007.12.026, 2008.

Box, G. E. P. and Tiao, G. C.:Bayesian Inference in Statistical Analysis, Wiley classic library ed., 1992.

Brunner, G. W.: SEIWR-HEC: HEC-RAS River Analysis System, User's Manual, Tech. Rep., US Army Corps of Engineers Institute for Water Resources Hydrologic Engineering Center (HEC), Davis, CA, USA, 2010.

Chatterjee, C., Förster, S., and Bronstert, A.: Comparison of hydrodynamic models of different complexities to model floods with emergency storage areas, Hydrol. Process., 22, 4695-4709, doi:10.1002/hyp.7079, 2012.

De Doncker, L., Troch, P., Verhoeven, R., Bal, K., Meire, P., and Quintelier, J.: Determination of the Manning roughness coefficient influenced by vegetation in the river Aa and Biebrza river, Environ. Fluid Mech., 9, 549-567, doi:10.1007/s10652009-9149-0, 2009.

Di Baldassarre, G., Schumann, G., Bates, P. D., Freer, J. E., and Beven, K. J.: Flood-plain mapping: a critical discussion of deterministic and probabilistic approaches, Hydrol. Sci. J., 55, 364376, doi:10.1080/02626661003683389, 2010.

Domeneghetti, A., Castellarin, A., and Brath, A.: Assessing ratingcurve uncertainty and its effects on hydraulic model calibration,
Hydrol. Earth Syst. Sci., 16, 1191-1202, doi:10.5194/hess-161191-2012, 2012.

Falacinski, P., Kuzniar, P., Wilk, E., Danilewicz, M., and Klimiuk, W.: Changes in the vertical water level and morphology of the bottom of the river channel in Warsaw reach of the Vistula River - Materials in the light of archives and measurements from year 2008, Technical report, Warsaw University of Technology, Faculty of Environmental Engineering, 2009.

Franz, D. D. and Melching, C. S.: Water-Resources Investigations Report 96-4240, Geological Survey, Washington, DC, USA, 1996.

Fread, D. L.: Flood routing models and manning n, in: Channel Flow Resistance: Centennial of Manning Formula, edited by: Yen, B. C., Water Resources Publication, Littleton, Colorado 80161, USA, 421-435, 1992.

Grayson, R. B., Moore, I. D., and McMahon, T. A.: Physically based hydrologic modelling: 2. Is the concept realistic?, Water Resour. Res., 28, 2659-2666, doi:10.1029/92WR01259, 1992.

Hankin, B. G., Hardy, R., Kettle, H., and Beven, K. J.: Using CFD in a GLUE framework to model the flow and dispersion characteristics of a natural fluvial dead zone, Earth Surf. Proc. Land., 26, 667-687, doi:10.1002/esp.214, 2001.

Horritt, M. S.: Calibration of a two-dimensional finite element flood flow model using satellite radar imagery, Water Resour. Res., 36, 3279-3291, doi:10.1029/2000WR900206, 2000.

Horritt, M. S. and Bates, P. D.: Evaluation of 1D and 2D numerical models for predicting river flood inundation, J. Hydrol., 268, 8799, doi:10.1016/S0022-1694(02)00121-X, 2002.

Hydroprojekt: Comprehensive regional flood protection program Vistula river basin in the Central Regional Water Management Board in Warsaw, Technical report, Warsaw, Poland, 1999.

Kitkowski, K. and Nieznanski, P.: Floodplain maps in the Odra valley in the Lower Silesia province, Gospodarka Wodna, 3110112, 2009 (in Polish).

Krzysztofowicz, R.: Bayesian system for probabilistic river stage forecasting, J. Hydrol., 268, 16-40, doi:10.1016/S00221694(02)00106-3, 2002.

Kuzniar, P.: 1-in-500 year flood in Warsaw according to historical materials and computer simulations, in: Flood 1997, Forum Naukowo-Technicze, IMGW, Warszawa, 2, 143-155, 1997.

Magnuszewski, A., Gutry-Korycka, M., and Szydlowski, M.: Two dimensional modelling of flood zones in the Vistula River Valley in Warsaw, Geographia Polonica, 82, 79-88, 2009.

Mitosek, H. T., Strupczewski, W. G., and Singh, V. P.: Toward an Objective Choice of an Annual Peak Distribution, ICHE, Warsaw, Poland, 2002.

Mugler, C., Planchon, O., Patin, J., Weill, S., Silvera, N., Richard, P., and Mouche, E.: Comparison of roughness models to simulate overland flow and tracer transport experiments under simulated rainfall at plot scale, J. Hydrol., 402, 25-40, doi:10.1016/j.jhydrol.2011.02.032, 2011.

Pappenberger, F., Matgen, P., Beven, K. J., Henry, J. B., Pfister, L., and Fraipont, P.: Influence of uncertain boundary conditions and model structure on flood inundation predictions, Adv. Water Resour., 29, 1430-1449, doi:10.1016/j.advwatres.2005.11.012, 2006.

Radczuk, L., Szymkiewicz, R., Jelowicki, J., Zyszkowska, W., and Brun, J.-F.: Determination of flood hazard zones, Drukarnia Oficyny Wydawniczej READ-ME, Lodz, Poland, 2001. 
Romanowicz, R. J. and Beven, K. J.: Estimation of flood inundation probabilities as conditioned on event inundation maps, Water Resour. Res., 39, 1073, doi:10.1029/2001WR001056, 2003.

Romanowicz, R. J. and Beven, K. J.: Comments on generalised likelihood uncertainty estimation, Reliab. Eng. Syst. Safe, 91, 13151321, doi:10.1016/j.ress.2005.11.030, 2006.

Romanowicz, R. J., Beven, K. J., and Tawn, J.: Evaluation of predictive uncertainty in nonlinear hydrological models using a Bayesian approach, in: Statistics for the Environment 2, Water Related Issues, edited by: Barnett, V. and Turkman, K. F., Wiley, Chichester, UK, 297-315, 1994.

Romanowicz, R. J., Beven, K. J., and Tawn, J.: Bayesian calibration of flood inundation models, in: Floodplain Processes, edited by: Anderson, M. G., Walling, D. E., and Bates, P. D., John Wiley and Sons, Chichester, UK, 333-360, 1996.

Romanowicz, R. J., Kiczko, A., and Osuch, M.: Determination of flood hazard maps, theory and practice, hydrology in engineering and water management, Monografie Komitetu Inzynierii Środowiska Polskiej Akademii Nauk (Polish Academy of Sciences Environmental Engineering Committee), Warsaw, Poland, 68, 337-346, 2010.

Romanowicz, R. J., Osuch, M., and Wallis, S.: Modelling of solute transport in rivers under different flow rates: a case study without transient storage, Acta Geophys., 61, 98-125, doi:10.2478/s11600-012-0050-8, $2013 \mathrm{a}$.

Romanowicz, R. J., Kiczko, A., Karamuz, E., and Osuch, M.: Derivation of flood-risk maps for the Warsaw reach of the river Vistula, in: Conference Proceedings "Flood Estimation and Analysis in a Variable and Changing Environment" Volos 2012, submitted, 2013b.

Smith, P., Beven, K. J., and Tawn, J. A.: Informal likelihood measures in model assessment: theoretic development and investigation, Adv. Water Resour., 31, 1087-1100, doi:10.1016/j.advwatres.2008.04.012, 2008.
Strupczewski, W. G., Weglarczyk, S., and Singh, V. P.: Model error in flood frequency estimation, Acta Geophys., 50, 279-319, 2002.

Strupczewski, W. G., Kochanek, K., and Singh, V. P.: On the informative value of the largest sample element of log-Gumbel distribution, Acta Geophys., 55, 652-678, doi:10.2478/s11600-0070027-1, 2007.

Strupczewski, W. G., Bogdanowicz, E., and Kochanek, K.: Disciussion of "Synthetic design hydrographs based on distribution functions with finite support" by Francesco Serinaldi and Salvatore Grimaldi, J. Hydrol. Eng., 16, 434-446, doi:10.1061/(ASCE)HE.1943-5584.0000339, 2011.

Tarantola, A.: Inverse Problem Theory, Elsevier, Amsterdam, 1987.

US Interagency Advisory Committee on Water Data: Guidelines for determining flood flow frequency, Bulletin 17B, US Dept. Interior, US Geological Survey, Office of Water Data Coordination, Reston, VA, 1982.

Werner, M. G. F.: A comparison of flood extent modelling approaches through constraining uncertainties on gauge data, Hydrol. Earth Syst. Sci., 8, 1141-1152, doi:10.5194/hess-8-11412004, 2004.

Wierzbicki, G., Ostrowski, P., Mazgajski, M., and Bujakowski, F.: Using VHR multispectral remote sensing and LIDAR data to determine the geomorphological effects of overbank flow on a floodplain (the Vistula River, Poland), Geomorphology, 183, 7381, doi:10.1016/j.geomorph.2012.06.020, 2012.

Yen, B. C.: Open channel flow resistance, J. Hydraul. Eng.-ASCE, 128, 20-39, doi:10.1061/(ASCE)0733-9429(2002)128:1(20), 2002.

Yue, S., Ouarda, T. B. M. J., Bobee, B., Legendre, P., and Bruneau, P.: Approach for describing statistical properties of flood hydrograph, J. Hydrol. Eng., 7, 147-153, doi:10.1061/(ASCE)1084-0699(2002)7:2(147), 2002. 